\title{
ANÁLISE CROMATOGRÁFICA/OLFATOMÉTRICA (CG/O) DE COMPOSTOS VOLÁTEIS DE MEL EXTRAÍDOS POR SPME
}

\author{
V. H. S. RODRIGUES, V. B. XAVIER e E. CASSEL \\ Pontifícia Universidade Católica do Rio Grande do Sul, Faculdade de Engenharia \\ Email para contato: victor.rodrigues.001@acad.pucrs.br
}

\begin{abstract}
RESUMO - O mel é um produto natural obtido a partir do néctar das flores e de excreções de abelhas. Suas propriedades estão diretamente vinculadas à origem botânica do néctar usado, cuja identificação depende de análise microscópica do pólen das flores existentes no mesmo. O presente estudo avalia a possibilidade de classificar o mel por cromatografia gasosa/olfatometria $(\mathrm{CG} / \mathrm{O})$, uma técnica híbrida que combina o poder de separação da CG com a seletividade e a sensibilidade específicas do nariz humano. Foram analisados dois tipos de mel: mel de Eucalipto e mel de Quitoco. Para extração dos compostos voláteis foi utilizada a técnica de SPME (Solid-Phase Microextraction), uma técnica de extração de amostras que apresenta vantagens como a economia de tempo e solvente. Para os experimentos foram utilizados $5 \mathrm{~g}$ de mel, inicialmente à temperatura ambiente. A determinação aromática dos constituintes das amostras foi realizada por seis avaliadores (em triplicata) para aumentar a confiabilidade dos resultados. As análises cromatográficas apresentaram compostos com aromas distintos, a se destacar os aromas: mato/doce/floral atribuído ao composto fenil etil álcool (presente nas duas amostras), doce/morango/mel/floral (composto não identificado do mel de Eucalipto) e citral/nozes/floral (composto não identificado do mel de Quitoco).
\end{abstract}

\section{INTRODUÇÃO}

O mel é um alimento natural líquido, viscoso e adocicado. Ele é elaborado a partir do néctar das flores e de secreções de partes vivas de determinadas plantas ou ainda de excreções de insetos sugadores de plantas, no qual abelhas coletam, transformam, combinam e deixam maturar nos favos das colmeias. Açúcares (monossacarídeos) e água são seus principais constituintes. O restante são vitaminas, minerais, enzimas, compostos orgânicos aromáticos, aminoácidos livres e numerosos compostos voláteis. Esta menor fração da composição total, referente aos compostos voláteis, é responsável pelas propriedades organolépticas e nutricionais do mel. A composição química do mel é altamente dependente da sua fonte botânica (Manyi-Loh et. al., 2011).

Sabe-se que apenas uma pequena parte do grande número de compostos voláteis que ocorrem em uma matriz aromática contribui para percepção do seu odor. Além disso, essas moléculas não contribuem igualmente para o perfil de aroma global de uma amostra, portanto a resposta gerada na análise cromatográfica, não necessariamente corresponde aos resultados sensoriais obtidos pelas análises olfatométricas (Xavier, 2011). A cromatografia gasosa/olfatometria $(\mathrm{CG} / \mathrm{O})$ é a metodologia analítica indicada para tais análises, pois permite a avaliação do odor de componentes ativos de misturas complexas, através da correlação 
específica com os picos cromatográficos de interesse; isso é possível porque as substâncias eluídas são percebidas simultaneamente por dois detectores: o detector do cromatógrafo e o sistema olfativo humano (van Baren, 2008). A correta identificação dos picos aromáticos ativos pode ser extremamente complicada devido às amostras apresentarem dezenas de compostos. A cromatografia gasosa/espectrometria de massas é a técnica mais utilizada na identificação dos compostos voláteis presentes nos alimentos (Goodner e Rouseff, 2011).

Dentre os diversos tipos de mel, este trabalho ateve-se a dois méis: mel de Eucalipto e mel de Quitoco. A partir da definição das amostras, a meta deste estudo foi propor e construir uma metodologia de classificação de méis como alternativa à análise microscópica de pólens. Para isso se empregou a análise de identificação dos compostos voláteis dos méis por cromatografia e a análise sensorial resultante da olfatometria.

\section{MATERIAIS E MÉTODOS}

\subsection{Amostras de mel}

Para os testes com mel, foram utilizadas amostras de mel de Eucalipto e mel de Quitoco. As amostras foram fornecidas pelo Instituto do Meio Ambiente e dos Recursos Naturais da PUCRS. Elas estavam cristalizadas e apresentavam coloração dourada, sendo que a amostra do mel de Eucalipto estava levemente escura. Ambas foram mantidas a temperatura ambiente antes das análises dentro de um vial com septo.

\subsection{Microextração em Fase Sólida (SPME)}

Os compostos voláteis dos méis foram extraídos pelo método de Microextração em Fase Sólida (SPME). Na SPME utiliza-se uma fibra ótica de sílica fundida, recoberta com um adsorvente adequado. A fibra se encontra acondicionada dentro de uma espécie de agulha em um amostrador semelhante a uma seringa, ficando exposta somente no momento da extração (método Headspace). (Orlando et al, 2009). Para os experimentos foram utilizados 5,0 g de mel, inicialmente à temperatura ambiente. A amostra, dentro de um vial de $20 \mathrm{~mL}$, foi aquecida até $70^{\circ} \mathrm{C}$ com o auxílio de uma placa de aquecimento, mantendo-se assim por 30 minutos; tempo esse denominado de tempo de equilíbrio. Após este período, a fase volátil é exposta à fibra por 30 minutos na temperatura de $70^{\circ} \mathrm{C}$, para adsorver os compostos voláteis. Uma vez transcorrido este processo, a fibra é injetada no cromatógrafo manualmente, ficando exposta por 2 minutos aos gases eluentes do equipamento. $\mathrm{O}$ processo pode ser resumido através da Figura 1.

\subsection{Análise de Cromatografia Gasosa/Olfatométria (CG/O)}

Para a realização da análise cromatográfica/olfatométrica, as amostras foram injetadas em um cromatógrafo gasoso equipado com um sistema de detecção por ionização de chama (FID) e um compartimento para avaliação sensorial (Sniffing Port). A coluna cromatográfica separação utilizada para o fracionamento dos compostos voláteis foi uma coluna capilar de sílica HP-5MS revestida com 5\% de fenil metil silox $(30 \mathrm{~m}$ x $250 \mu \mathrm{m}$ i.d., $0,25 \mu \mathrm{m}$ de espessura de face). $\mathrm{O}$ injetor, o olfatômetro e o detector FID estavam a $250^{\circ} \mathrm{C}$. O programa de 
temperatura foi o seguinte: $60^{\circ} \mathrm{C}$ por 4 min, aumentando a $5{ }^{\circ} \mathrm{C} / \mathrm{min}$ até $180^{\circ} \mathrm{C}$, a $20^{\circ} \mathrm{C} / \mathrm{min}$ até $250^{\circ} \mathrm{C}$, e a $250^{\circ} \mathrm{C}$ por $5 \mathrm{~min}$ (total: $36,50 \mathrm{~min}$ ). A linha de transferência utilizada para

Figura 1 - Processo de Microextração em Fase Sólida (SPME): (a) etapa de adsorção dos voláteis da amostra; (b) etapa de injeção dos compostos adsorvidos no CG/O.

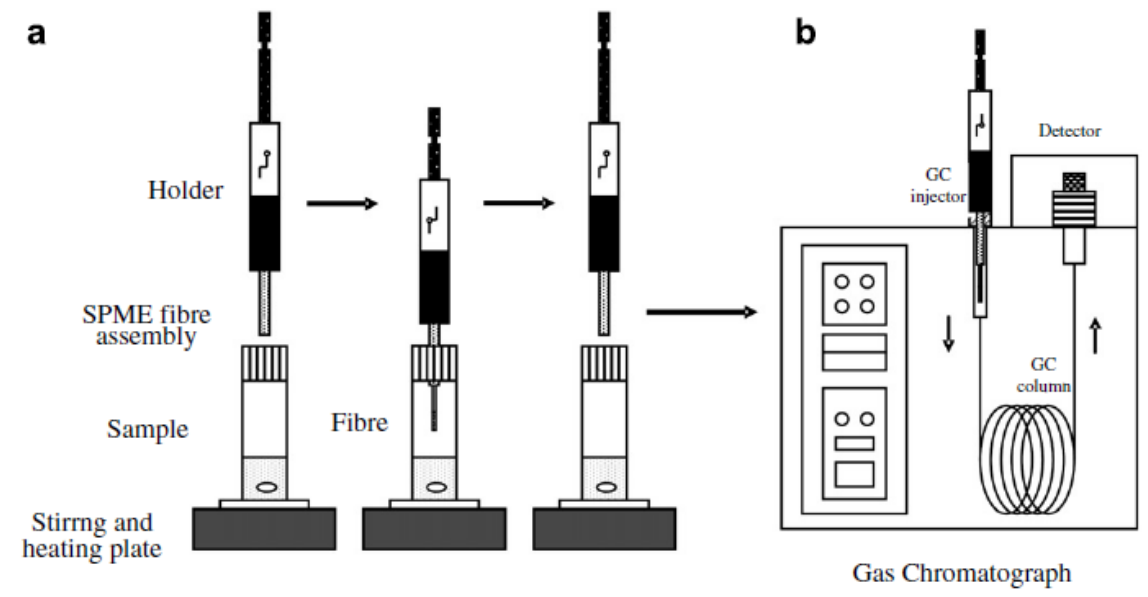

Fonte: Cuevas-Glory, 2007.

carrear a amostra até o compartimento de avaliação sensorial foi mantida a $250{ }^{\circ} \mathrm{C}$. Um fluxo constante de gás auxiliar (nitrogênio) de $5 \mathrm{~mL} / \mathrm{min}$ foi utilizado durante a análise. $\mathrm{O}$ dispositivo Sniffing Port é equipado com um umidificador com o objetivo de reduzir a desidratação da mucosa nasal durante a análise sensorial. A metodologia proposta por van Baren (2008) foi a base para a execução das análises. A fim de se obter uma maior confiabilidade nos resultados, foram selecionados seis avaliadores, previamente treinados, para a realização da análise olfatométrica. Cada um desses avaliadores relatou as seguintes informações: tempo, em relação ao início da análise, em que sentiu um determinado aroma, descrição do aroma e intensidade do odor em uma escala de números inteiros de 1 a 5 , sendo 1 a menor intensidade e 5 a maior intensidade. A partir das respostas dos avaliadores é gerada uma nova grandeza que relaciona intensidade e frequência de detecção, denominada Frequência Modificada (FM). A Equação representa a forma de cálculo da FM (Dravnieks, 1985).

$$
F M(\%)=\sqrt{F(\%) \cdot I(\%)}
$$

(1),

onde $\mathrm{F}(\%)$ é a frequência, em termos percentuais, de detecção de um aroma entre o universo de avaliadores e $\mathrm{I}(\%)$ é a intensidade média de um atributo aromático em relação à escala, sendo $100 \%$ correspondendo a média 5 . Se um aroma possui $100 \%$ de FM quer dizer que o mesmo foi detectado por todos os avaliadores e com a máxima intensidade.

\subsection{Análise de Cromatografia Gasosa/Espectrometria de Massas (CG/EM)}

Para a identificação da composição das amostras de mel foi utilizado um CG/EM. O programa de temperatura foi o mesmo utilizado no $\mathrm{CG} / \mathrm{O}$. As demais condições do 
cromatógrafo foram: o gás de arraste foi hélio com vazão $0,8 \mathrm{~mL} / \mathrm{min}$; a temperatura da interface, $250^{\circ} \mathrm{C}$; modo MS EI; tensão de EI, 70eV; intervalo de massas de aquisição, $\mathrm{m} / \mathrm{z}$ 40450 .

\section{RESULTADOS E DISCUSSÕES}

Os resultados da análise química de identificação e quantificação dos compostos presentes na fase volátil das amostras de mel, realizada por CG/EM, são apresentados na Tabela 1, sendo que foi definido adicionar os compostos com área maior que 1,0\%.

Tabela 1 - Análise Cromatográfica CG/EM das amostras de mel

\begin{tabular}{|c|c|c|c|}
\hline \multirow{2}{*}{ COMPOSTO $^{\mathrm{a}}$} & \multirow{2}{*}{$\mathbf{I R}^{\mathbf{b}}$} & \multicolumn{2}{|c|}{ Área $^{\mathrm{c}}(\%)$} \\
\hline & & Eucalipto & Quitoco \\
\hline ácido 2-metil-butanóico & 832 & 1,30 & - \\
\hline canfeno & 944 & 4,96 & - \\
\hline benzaldeído & 949 & 6,21 & - \\
\hline benzeno acetaldeído & 1036 & 1,12 & - \\
\hline isobutil angelato & 1046 & 1,00 & 19,60 \\
\hline formato de benzila & 1075 & 5,71 & 16,07 \\
\hline $\begin{array}{l}\text { óxido de trans-linalool } \\
\text { (furanóide) }\end{array}$ & 1080 & - & 2,83 \\
\hline linalol & 1091 & 1,00 & 4,95 \\
\hline fenil etil álcool & 1106 & 16,50 & 16,00 \\
\hline isoforona & 1117 & - & 1,14 \\
\hline cânfora & 1145 & 1,07 & 0,25 \\
\hline trans-b-terpineol & 1156 & 1,53 & 1,41 \\
\hline 1-fenil etil acetato & 1192 & 2,45 & 3,43 \\
\hline nerol & 1230 & - & 1,09 \\
\hline neral & 1237 & - & 1,01 \\
\hline geraniol & 1249 & 2,34 & - \\
\hline n-decanol & 1263 & 1,00 & 1,36 \\
\hline decanoato de metila & 1325 & 1,23 & 1,00 \\
\hline aldeído limoneno & 1330 & 7,44 & 4,25 \\
\hline $\begin{array}{l}\text { 3-hidroxi-4-fenil-2- } \\
\text { butanona }\end{array}$ & 1340 & - & 4,88 \\
\hline 2-fenil-etil-propanoato & 1349 & 8,73 & - \\
\hline 2-tridecanona & 1497 & 1,48 & - \\
\hline n-pentadecano & 1502 & 9,10 & 2,86 \\
\hline 7-epi-a-eudesmol & 1661 & 5,36 & - \\
\hline n-tetradecanol & 1672 & 5,44 & 3,01 \\
\hline ocidol & 1834 & 1,03 & 3,14 \\
\hline
\end{tabular}


$\mathrm{a}=$ compostos identificados pela comparação de seus espectros de massa e índices de retenção com a biblioteca Adams (2007); compostos com área $\geq 1 \%$; ${ }^{\mathrm{b}} \mathrm{IR}$ = índice de retenção calculado em relação a uma série de alcanos; cÁrea = área percentual de cada pico em relação à área total do cromatograma.

Por sua vez, a CG/O foi capaz de identificar uma grande variabilidade de aromas para as duas espécies. As Tabelas 2 e 3 apresentam os compostos identificados que apresentaram FM maior que 40. A Tabela 4 apresenta os compostos identificados tanto por CG/O quanto por CG/EM.

Tabela 2 - Cromatografia Gasosa/Olfatometria para o mel de Eucalipto

\begin{tabular}{cccc}
\hline IR & Tempo (min) & Descrição do aroma & FM \\
\hline 832 & 4,95 & doce & 41 \\
849 & 5,28 & doce/morango/mel/floral & 60 \\
936 & 7,60 & madeira/grama & 43 \\
974 & 8,81 & doce/refrigerante & 45 \\
1015 & 10,08 & frutal & 45 \\
1106 & 12,93 & mato/doce/floral & 45 \\
1137 & 13,86 & eucalipto/floral/caramelo & 47 \\
1171 & 14,87 & cloro & 41 \\
1736 & 28,79 & mel/floral & 43 \\
\hline
\end{tabular}

Tabela 3 - Cromatografia Gasosa/Olfatometria para o mel de Quitoco.

\begin{tabular}{cccc}
\hline IR & Tempo (min) & Descrição do aroma & FM \\
\hline 942 & 7,828 & linalol & 45 \\
1075 & 11,996 & amargo/refrescante & 56 \\
1091 & 12,475 & eucalipto/chá/camomila & 60 \\
1106 & 12,900 & mato/doce/floral & 45 \\
1267 & 17,642 & citral/nozes/floral & 60 \\
1408 & 21,404 & floral/coco fruta & 61 \\
\hline
\end{tabular}

Tabela 4 - Compostos identificados por CG/EM e CG/O dos compostos de mel

\begin{tabular}{cccccc}
\hline Mel & IR & Composto & Área(\%) & Aroma & FM(\%) \\
\hline \multirow{2}{*}{ Eucalipto } & 832 & Ácido 2-metil-butanóico & 1,30 & doce & 41 \\
& 1106 & fenil etil álcool & 16,50 & mato/doce/floral & 45 \\
\hline \multirow{2}{*}{ Quitoco } & 1075 & formato de benzila & 16,07 & amargo/refrescante & 56 \\
& 1091 & linalol & 4,95 & eucalipto/chá/camomila & 60 \\
\hline
\end{tabular}

Os resultados das análises cromatográficas dos dois tipos de mel em estudo apresentam compostos aromáticos com aromas distintos, com destaque para o aroma de doce/morango/mel/floral encontrado para o mel de Eucalipto e coco/floral para o mel de Quitoco. Contudo apenas dois, para o mel de Eucalipto, e três, para o mel de Quitoco, dos aromas percebidos pelos analisadores foram identificados por CG/EM, ou seja, a grande maioria dos aromas encontrados provém de constituintes minoritários na amostra. Logo, os 
odores mais perceptíveis (maiores valores de FM) não correspondem necessariamente aos compostos majoritários presentes nos voláteis do mel. Isto pode ser observado nos compostos formato de benzila (16,07\%) e linalol (4,95\%) para o mel de Quitoco que apresentaram 56 e 60 de FM, respectivamente. Esta constatação é observada em outras matrizes, também analisadas por $\mathrm{CG} / \mathrm{O}$, como, por exemplo, em óleos essenciais de espécies de Baccharis (Xavier, 2011) e de Mulinum spinosum (Cav.) Persoon (van Baren, 2008). Alguns compostos majoritários na análise química obtiveram baixo ou nenhum aroma na análise olfatométrica, tais como: aldeído limoneno, 2-fenil-etil-propanoato e n-pentadecano (no mel de Eucalipto) e isobutil angelato (no mel de Quitoco).

\section{CONCLUSÕES}

O mel é um produto extremamente complexo e seus compostos aromáticos se apresentam em baixas concentrações. O presente estudo avaliou a possibilidade de classificar o mel por $\mathrm{CG} / \mathrm{O}$, como alternativa à análise microscópica do pólen (melissopalinologia) que é a técnica mais empregada atualmente. Segundo Cuevas-Glory et. al. (2007) e Manyi-Loh et. al. (2011), a melissopalinologia requer um analista muito experiente e é uma técnica muito demorada. A partir dos resultados se concluiu que a técnica de extração utilizada (SPME) mostrou-se eficiente na obtenção dos compostos voláteis de mel e a CG/O consolidou-se como técnica alternativa. Porém, ainda serão necessários estudos complementares para se estabelecer a técnica como forma de classificar méis, visto que se busca um ou mais compostos-chave que sejam capazes de identificar a origem do mel a partir da planta usada como fonte de matéria-prima.

\section{REFERÊNCIAS}

DRAVNIEKS A. Atlas of Odor Character Profiles, ASTM: Philadelphia, PA, p.354, 1985.

CUEVAS-GLORY, L. F.; PINO, J. A.; SANTIAGO, L. S.; SAURI-DUCH, E. A review of volatile analytical methods for determining the botanical origin of honey. Food Chemistry, v. 103, p. 1032-1043, 2007.

GOODNER, K.; ROUSEFF, R. In: Practical Analysis of Flavor and Fragrance Materials. Gas Chromatography/Olfactometry - GC/O. Wiley, p. 69-90, 2011.

MANYI-LOH, C. E.; NDIP, N. R.; CLARKE, A. M. Volatile Compounds in Honey: A Review on Their Involvement in Aroma, Botanical Origin Determination and Potencial Biomedical Activities. International Jounal of Molecular Sciences. v. 12, p. 9514-9532, 2011

ORLANDO, R. M.; Cordeiro, D. D.; Mathias, A. E. B.; Rezende, K. R.; Gil, E. S. PréTratamento de Amostras. Vita et Sanitas, Trindade/Go, n. 03, p. 122-139, 2009.

VAN BAREN, C. M. Composición química y actividades biológicas de una espécie aromática y medicinal de la estepa patagónica con potencial interés industrial: Mulinum spinosum (Cav.) Persoon. Tese de doutorado em Fármacia e Bioquímica. Cátedra de Farmacognosia. Universidade de Buenos Aires. Buenos Aires, 2008.

XAVIER, V. B. Investigação sobre compostos voláteis de espécies de Baccharis nativas do Rio Grande do Sul. Dissertação de Mestrado. Programa de Pós-Graduação em 
Engenharia e Tecnologia de Materiais. Pontifícia Universidade Católica do Rio Grande do Sul. Brasil. Porto Alegre, 2011. 